\title{
Subjetividade e clínica na atenção básica. narrativas, histórias de vida e realidade social
}

\author{
Subjectivity and a clinical approach in primary healthcare; \\ narratives, life histories and social reality
}

Rebeca Silva de Barros ${ }^{1}$ Carlos Botazzo ${ }^{2}$
${ }^{1}$ Diretoria de Atenção Básica, Secretaria de Saúde do Estado da Bahia (DAB/SAIS/ SESAB). Av. Dr. Enéas Carvalho de Aguiar. 05403-000 São Paulo SP. rebeca_usp@yahoo.com.br ${ }^{2}$ Pesquisador Científico, IS- Secretaria de Estado da Saúde/São Paulo

\begin{abstract}
The focus of this article is on oral healthcare in Primary Healthcare. We discuss the issue taking the relationship of listening-host-link as a focus debating on the existence of a dichotomy between clinical-collective health. This investigation, took place in Cotia, São Paulo State between July and December 2007, based on the following assumptions: 1) answer the user's relevant oral care problem; 2) remove the dental focus; 3) establish the case through anamnesis; and 4) use electronic scheduling, medical files and sterilization of the health unit. Listening to the complaint, the oral clinical examination and compilation of the clinic history were recorded in the medical file, without using dental records. To discuss the approaches in the clinical area, we list 8 'Patographic Histories.' The objectives of communication during consultation are to listen, perform an accurate diagnosis and interfere to alleviate suffering by restoring the corporal homeostasis and creating a bond by modifying technical references and clinical language. The bond is the result of dialogue, the acceptance of responsibilities of both the professional and the user and the resolution of their complaints and needs.
\end{abstract}

Key words Subjectivity, Anamnesis, Clinic, Primary Healthcare, Stomatology
Resumo O foco deste artigo é o cuidado em saúde bucal na Atenção Básica. Esta é lugar potencial para geração de encontros e produção de subjetividade. Por isso, discutiremos o tema tomando como foco a relação da escuta-acolhimento-vínculo debatendo sobre a existência de dicotomia entre clínica-saúde coletiva. Esta pesquisa-intervenção realizou-se de julho a dezembro de 2007 no município de Cotia-SP, a partir dos pressupostos: 1) atendimento ao problema bucal relevante para o usuário; 2) descentramento dentário; 3) constituição do caso clinico por meio da anamnese e 4) integração com os serviços da unidade. A escuta da queixa, o exame clínico bucal e o levantamento da história clínica foram registrados no prontuário, sem o uso de odontograma. Para discussão de abordagens na clínica, relataremos 08 'Hestórias Patográficas'. Os objetivos da comunicação na consulta são acolher, promover o diagnóstico seguro e interferir na evolução do sofrimento do outro restabelecendo a homeostasia corporal e produzindo vínculo, com modificação de referenciais teóricos e da linguagem clínica. O vínculo é resultado do diálogo, da assunção de responsabilidades tanto do profissional quanto do usuário e da resolução das suas queixas e necessidades.

Palavras-chave Subjetividade, Anamnese, História de Vida, Clínica, Atenção Básica, OdontoEstomatologia 


\section{Introdução}

A saúde bucal na Atenção Básica (AB), há tempos, é tema de reflexões na saúde coletiva e em departamentos de odontologia social emergindo quando a organização das ações e do cuidado em saúde bucal no Sistema Única de Saúde (SUS) está em pauta.

A Política Nacional de Saúde Bucal apontou diretrizes para reorganizar as ações e reorientar o modelo de atenção em saúde bucal no país, tendo como eixo central o conceito do cuidado propondo pressupostos para a ampliação e a qualificação da saúde bucal na perspectiva da integralidade da atenção. Destes destacam-se: qualificação da $A B$, garantindo qualidade e resolubilidade; $A B$ articulada com a rede de serviços; integralidade nas ações, articulando o individual e o coletivo, a promoção e a prevenção, o tratamento e a recuperação da saúde da população adscrita; política de educação permanente e política de financiamento para o desenvolvimento de ações ${ }^{1}$.

Há 20 anos, os adjetivos: ineficaz, ineficiente, monopolizadora, altamente custosa, tecnologicamente densa, elitista, iatrogênica e mutiladora, apontam os problemas da prática odontológica hegemônica no país².

Para modificar este modelo, percebemos tentativas de ruptura epistemológica com o pensamento odontológico dominante. Entre 1952 e 1992, surgiu a odontologia: sanitária, preventiva, social, simplificada, comunitária, integral e a saúde bucal coletiva $(\mathrm{SBC})^{3}$. Sendo a SBC, aquela que provocou uma ruptura epistemológica apontando como referencial teórico para mudança de uma prática assistencial privatista para um modelo de atenção em saúde bucal ${ }^{4}$ causando impacto nas ações preventivas e de promoção da saúde, mas impactando em menor intensidade a produção do cuidado, mantendo a clínica em certa marginalidade nas discussões.

No SUS, a rotina clínica permanece centrada, em geral, no tratamento efetuado mecanicamente como linha de produção: o cirurgião-dentista recebe usuários, em sua maioria jovens, com cavitações e raízes residuais, e os libera com restaurações e suturas. Na lógica das ações programáticas, curetam-se cavidades e restauram-se dentes conferindo um tratamento completado. $\mathrm{E}$ os usuários entram mudos e saem calados. Indagamos se seria essa prática tradicional suficiente para a realização de uma clínica comprometida com a promoção da saúde e a afirmação da vida, seus aspectos, significados e representações, ou seria necessário buscar uma outra posição para o cuidado em saúde bucal que priorizasse a produção de subjetividade através da escuta do outro e no diagnóstico realizados em encontros na clínica que conferissem sentido à intervenção restauradora e/ou cirúrgica.

Há quem diga que realizar a escuta, proporcionar que o usuário dê vazão a seus incômodos depositando-os na clínica e construir o vínculo na relação de cuidado em saúde são atividades trabalhosas e atribuídas ao profissional sensivel portador de certa essência. Tal comentário, de pano de fundo ideológico, difunde-se por corredores de faculdades, corporações e unidades básicas de saúde (UBS) e encontra reforço em manuais de semiologia que frisam que a abordagem do paciente "é óbvio, não pode ser ensinada, dependendo exclusivamente da sensibilidade e tato do examinador"5 [grifo nosso].

Neste artigo, concentraremos a reflexão sobre o cuidado em saúde bucal como estratégia de qualificação da $A B$ questão essa que encontra lugar emergência no âmbito da gestão, do controle social, e na clínica como produtora de saúde no dia a dia do SUS, pois sabemos que as políticas de saúde efetuam-se se houver um trabalho (e um trabalhador na saúde) que as objetive no cotidiano do cuidado em saúde ${ }^{6}$.

Discutiremos o cuidado em saúde bucal na $\mathrm{AB}$ tomando como foco a relação da escuta, acolhimento e vínculo debatendo sobre a existência de dicotomia entre clínica e saúde coletiva. Para proporcionar a discussão sobre possíveis abordagens na clínica, utilizamos como recurso o relato de 08 Hestórias Patográficas que constituem-se como narrativas dos usuários que, através de suas falas, revelaram: queixas, incômodos, situações que viveram consciente e inconscientemente, e que encontraram existência material em seus corpos ${ }^{7}$.

\section{Percurso metodológico}

Este estudo, fruto de pesquisa de intervenção em atividade experimental em clínica na UBS do Portão realizado de julho a dezembro de 2007 no município de Cotia/ SP, foi partilhado com a equipe de saúde bucal da UBS e pactuado com os gestores e trabalhadores locais.

Os pressupostos para sua execução foram: atendimento aos problemas bucais mais relevantes para o usuário e não para o serviço (construção social da demanda); descentramento dentário (desprivilegiamento da cárie dentária como patologia-mãe ${ }^{8}$ ); constituição do caso clínico por meio da anamnese e utilização de agendamento 
eletrônico, prontuário único (PU), expurgo e esterilização da UBS.

$\mathrm{O}$ atendimento foi executado 03 vezes por semana (04 horas/período) sendo atendidos 08 usuários/período. A anamnese incluiu a escuta da queixa e o exame clínico bucal e o levantamento da história clínica (LHC), realizados em conversa em mesa para consulta (isto é, fora da cadeira odontológica), registrados no PU e sem uso de odontograma para anotação de achados clínicos. Já o exame físico (EF), incluindo boca e dentes, realizou-se na cadeira odontológica. Opcionalmente, o usuário acompanhava o exame por meio de um espelho de $13 \times 17 \mathrm{~cm}$, podendo observar, discutir sobre sua condição bucal e melhor negociar o seu projeto terapêutico ${ }^{9}$. Esta negociação foi garantida mesmo nos casos em que o usuário preferiu não visualizar sua própria boca durante o exame.

Os usuários, informados e esclarecidos quanto à natureza do trabalho como parte de projeto de pesquisa, foram convidados a participar como beneficiários da atividade, assinando termo de consentimento livre e esclarecido. O projeto foi aprovado pelo Comitê de Ética em Pesquisa do Instituto de Saúde em maio de 2007.

\section{Resultados}

Durante a atividade clínica, atendemos 184 usuários. Destes, a maior parte, concentrou-se entre as mulheres (Gráfico 1) e entre os usuários com idade entre 20 a 34 anos (Gráfico 2).Usou-se a denominação corrente de casos novos e, quando reagendados, retornos. No Quadro 1, observamse os motivos para consulta, apresentados pelos usuários, e os achados clínicos diagnosticados.

Neste artigo, concentramos a discussão em possíveis abordagens e destacamos, no Quadro 2, as depositações emergentes no diálogo clínico.

Para exemplificar as possibilidades de abordagens na clínica, apresentamos 08 Hestórias $\mathrm{Pa}$ tográficas selecionadas.

\section{Menina-Moça, 11 anos}

$\mathrm{O} 1^{\circ}$ encontro, realizado em julho em consulta de urgência, foi solicitado pela mãe que queixava-se de que a filha apresentava "sangramento na gengiva e que os dentes da frente estavam ficando moles". A menina estava em casa e a mãe informou que viriam devagar porque "a menina sentia muitas dores nas pernas e por isso andava muito devagar". A anamnese realizou-se com a menina sentada na cadeira odontológica e na presença da mãe. Durante o LHC, a mãe relatou a recorrência de infecções urinárias da filha que ficava "internada de $06 \mathrm{em} 06$ meses no Hospital de Cotia". No PU, do período de 2000 a 2005, havia registros das queixas quanto ao trato urinário, as prescrições e as internações. A menina se manteve calada durante toda a consulta.

Segundo a mãe, a filha engordou $18 \mathrm{~kg}$ em 02 meses aparentemente sem motivo. Apresentou a $1^{\text {a }}$ menstruação há 06 meses. Mais adiante corrigiu-se, informando que a $1^{\text {a }}$ menstruação fora aos 09 anos de idade. Relatou que a menina sentia dor de cabeça e atrás dos joelhos no período menstrual. Quando indagada sobre isso, a menina apontou para as pernas e não conseguiu definir a sintomatologia. "Ela está cansada de ser examinada e por isso não a levo às consultas médicas". A investigação deste caso clínico não encontrou possibilidade de ser aprofundada, pois o consultório não proporcionava a privacidade necessária à abordagem.

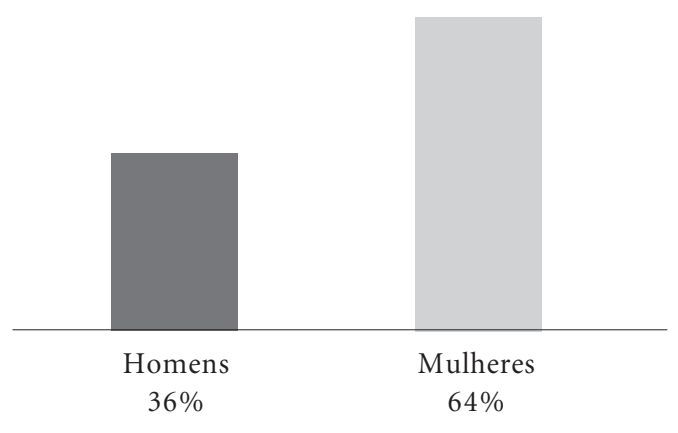

Gráfico 1. Distribuição de casos novos porsexo (\%).

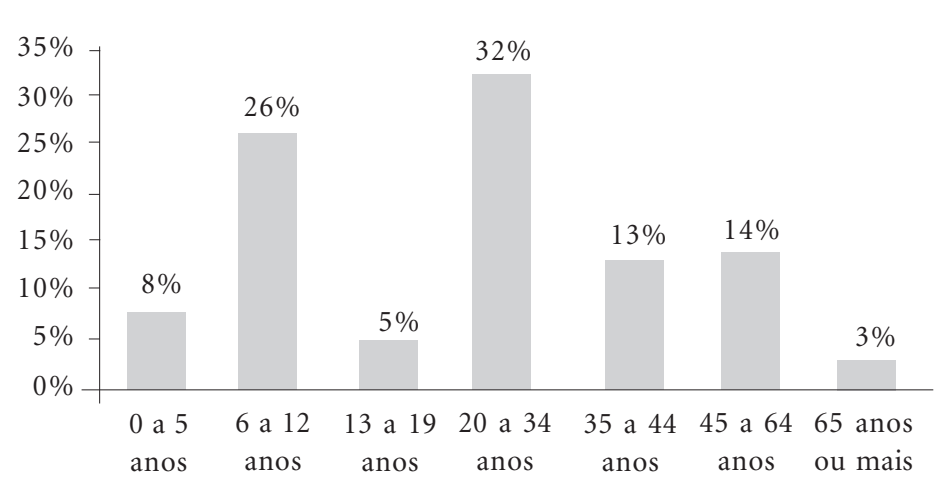

Gráfico 2. Distribuição de casos novos por faixa etária (\%). 
Quadro 1. Motivos para consulta e achados clínicos segundo localização

\begin{tabular}{|c|l|l|}
\hline Localização & \multicolumn{1}{|c|}{ Motivo para Consulta } & \multicolumn{1}{c|}{ Achado Clínico } \\
\hline Tecidos duros & $\begin{array}{l}\text { dente: amolecido, cariado, } \\
\text { amarelado, impactado e retido; } \\
\text { raízes residuais; fratura coronária }\end{array}$ & $\begin{array}{l}\text { fluorose; mancha branca; placa bacteriana; cárie } \\
\text { aguda; pulpite; amelogênese imperfeita; maloclusão; } \\
\text { giroversão dentária; ausência dentária; espícula } \\
\text { óssea; desgaste de esmalte dentário: abfração, } \\
\text { abrasão; diastema; agenesia }\end{array}$ \\
Tecidos Moles & $\begin{array}{l}\text { sangramento gengival; cisto de } \\
\text { erupção; abcessos agudos e } \\
\text { crônicos; afta; aumento de volume } \\
\text { em soalho de boca; formigamento } \\
\text { (coceira) na gengiva }\end{array}$ & $\begin{array}{l}\text { mordiscamento de bochecha; anquiloglossia; } \\
\text { gengivite leves e severas; estomatite por uso de } \\
\text { dentadura; periodontite crônica leves e severas; } \\
\text { comunicação buco-sinusal; herpes labial; lesão em } \\
\text { periápice dentário; ressecamento labial (queilite } \\
\text { actínica); língua geográfica, língua fissurada; } \\
\text { queimadura em palato; grânulos de Fordyce; rânula } \\
\text { e lesões traumáticas }\end{array}$ \\
\hline Outros & $\begin{array}{l}\text { exame preventivo; dor aguda; } \\
\text { sensibilidade com bebida fria/ } \\
\text { quente; prótese mal adaptada; } \\
\text { sensação de aspereza nos dentes; } \\
\text { mau hálito ou mau cheiro na boca }\end{array}$ & $\begin{array}{l}\text { dor orofacial; crepitação da articulação temporo- } \\
\text { mandibular (ATM); desvio mandibular; respiração } \\
\text { bucal; ronco durante o sono; sucção exagerada com } \\
\text { o uso de chupeta e mamadeira por crianças de até } \\
\text { 07 anos de idade, onicofagia, apertamento dentário } \\
\text { e bruxismo; cálculo }\end{array}$ \\
\hline
\end{tabular}

Quadro 2. Depositações emergentes no diálogo clínico

\begin{tabular}{|l|l|}
\hline \multicolumn{1}{|c|}{ Tipo } & \multicolumn{1}{c|}{ Depositação } \\
\hline Social & $\begin{array}{l}\text { subemprego/desemprego; desejo de ingressar/concluir formação profissional, imigração/ } \\
\text { migração, uso de álcool, tabaco e drogas ilícitas }\end{array}$ \\
\hline Familiar & $\begin{array}{l}\text { relacionamento conjugal e familiar (como divórcios, violência doméstica, planejamento } \\
\text { familiar), conflitos e inseguranças na educação dos filhos (como superproteção e 'medo' de } \\
\text { perdê-los por doença, violência ou ação do conselho tutelar) }\end{array}$ \\
\hline Psíquica & $\begin{array}{l}\text { nervosismos (com relato de uso prolongado de medicação calmante para os nervos por } \\
\text { crianças de 03 anos de idade), vergonha decorrente de mutilações bucais e iatrogenias, } \\
\text { síndrome do pânico, ansiedade, depressão, dificuldade de aprendizagem, distúrbios do sono, } \\
\text { sonambulismo e insônia. }\end{array}$ \\
\hline
\end{tabular}

A mãe entregou uma ficha de encaminhamento da filha para o Serviço de Endodontia do Centro de Especialidades Odontológicas (CEO). Estava muito preocupada com o tempo de espera para consultas. No EF, havia interferência oclusal entre dentes superiores e inferiores com pequena mobilidade de um dos incisivos inferiores e poucas cavitações. Não havia abaulamento da tábua óssea, nem presença de fístula. Solicitou-se retorno.

Retornou sozinha e bastante quieta como no $1^{\circ}$ encontro. Ao EF, à palpação da tábua óssea vestibular, próxima à espinha nasal, acusou dor. Havia presença de fístula na região, o que levantou a suspeita de que, anteriormente, a menina sofrera um trauma dentário. Todavia, a paciente negou queda ou trauma buco-dentário. Na ficha clínica, arquivada no consultório odontológico, encontravam-se as seguintes anotações: “(...), 07 anos. Restauração em resina composta cor B2 ângulo incisal do 11 ”. Não havia registro sobre o trauma nem outra informação sobre o caso. Somente a memória da menina, que, no entanto, continuava a negar a ocorrência do fato. O caso clínico exigia uma intervenção endodôntica, porém, na ausência da mãe, o atendimento foi suspenso tendo sido solicitada uma radiografia periapical e retorno acompanhado pela responsável. Nunca mais retornou. 


\section{Caçadora de $\mathrm{Si}, 34$ anos}

No $1^{\circ}$ encontro, realizado em julho em consulta agendada, veio junto com uma vizinha. Cabisbaixa, tinha um olhar triste. Um pouco evasiva, manifestou o desejo de fazer um "check up". Solicitou-se que elaborasse melhor sua queixa apontando com clareza o que realmente a incomodava. Reclamou da sensibilidade dolorosa ao ingerir alimentos doces e de sangramento gengival espontâneo. No LHC, destacou depressão e hipertensão. No PU, as anotações referiam-se aos anos de 2006 e 2007. Seu "percurso" na unidade incluía, além da saúde bucal, controle da hipertensão, dermatologia, ginecologia e, desde 2006, consultas regulares com a psiquiatra da UBS.

Investigou-se a razão de sua tristeza. Seu sofrimento começara com a perda do emprego. "Fui acusada de algo que não fiz e não pude provar o contrário. Perdi o emprego". Trabalhava num berçário mas não detalhou os motivos da acusação. Contou sobre a síndrome do pânico, das crises de choro, da insônia, da dificuldade de sair sozinha e de seu desânimo pela vida. Morava sozinha na casa dos fundos no mesmo terreno em que seus pais também viviam. Desejava "voltar a se cuidar". Segundo o PU, em abril de 2006, permaneceu "três dias sem tomar banho". Em dezembro de 2006, queixava-se de "sentir cheiro forte no nariz". Até início de 2007, segundo registros, mesmo sob medicação antidepressiva, não havia sinal de melhora de seu quadro.

Ao EF, havia presença de gengivite intensa, gengivas edemaciadas, sangramento gengival à sondagem, placa visível, restaurações antigas tanto em resina quanto em amálgama e uma fístula em região de incisivos superiores. A usuária acompanhou o exame pelo espelho, podendo-se discutir e negociar o tratamento. Manifestava o desejo de trocar as restaurações antigas. Explicou-se que com sua condição bucal não era aconselhável iniciar a intervenção restauradora. Foi orientada quanto à escovação e uso do fio dental e encaminhada para o Serviço de Endodontia do CEO solicitando retorno.

Após um mês, retornou, dessa vez, sozinha. $\mathrm{Na}$ sala de espera, bordava panos de prato. Entrou no consultório bastante animada. Contou sobre as caminhadas diárias e sobre os bordados. Estava feliz com a melhora de sua condição bucal. Indagada sobre sua melhora, a resposta imediata foi "estou 40\% melhor!" Percebi que o sangramento diminuiu muito!". Procurou agendar consulta no CEO. Mas "não tinha vaga". No $\mathrm{EF}$, verificou-se diminuição da gengivite, do odor bucal e da placa visível, iniciando-se as intervenções clínicas pelo tratamento periodontal.

\section{Mama África, 34 anos}

No $1^{\circ}$ encontro, realizado em agosto em consulta agendada, muito quieta, sentou-se à mesa para consulta. Mantinha as costas arqueadas para frente apresentando clara tensão muscular nos ombros. Indagada sobre seu incômodo bucal, reclamou: "Sinto uma gastura quando como". Evitava mastigar do lado direito e o dente que a incomodava estava com um curativo. Relatou morder as bochechas. Não relatou problemas médicos, exceto quando perguntada sobre possíveis dores de cabeça. "Sim. Sinto muita dor. Só ontem tomei 04 comprimidos (02 Tylenol e 02 Neosaldina) e mesmo assim não consegui dormir. E hoje já tomei mais uma Neosaldina”. Há 04 anos, tinha dores de cabeça que se iniciavam à tarde e permaneciam por até 04 dias. Não as associava a nenhuma situação, pessoa ou sentimento. Sobre a localização das dores, relatou "sentir o olho pesado" e sinalizou para a base do crânio e na região do músculo temporal.

Pedira demissão da confeitaria da região após 03 anos de trabalho. "Cansei do trabalho. Era muito estressante. No momento, estou em casa" e faz bicos como diarista. Tem 03 filhas e 01 filho. Viveu um casamento de 16 anos. Nos 05 últimos anos, conviveu com problemas conjugais. Há 08 meses, separou-se do marido. Queixou-se de que ele não pagava a pensão para os filhos e que ela assumira todas as despesas da casa. "Sinto que tenho muita responsabilidade nas costas". É migrante nordestina e vive em São Paulo há 12 anos.

Ao EF, no exame extra-bucal, à palpação da região do ângulo da mandíbula e da ATM referiu intensa dor, também nos músculos mastigatórios. Havia sinais de mordiscamento da mucosa jugal em ambos os lados. Associou esse hábito à ansiedade. Como não havia condições para intervir, foi dispensada e solicitou-se que tentasse associar os episódios de dor de cabeça a alguma situação, pessoa ou sentimento. Após 01 mês, retornou. Resolvera o problema da "gastura" em consultório da rede privada. Continuava com dores de cabeça, agora, diminuídas. Os episódios de dor de cabeça foram associados à preocupação.

\section{Primavera nos Dentes, 29 anos}

No $1^{\circ}$ encontro, realizado em agosto em consulta agendada, junto com o marido, pois ambos iriam consultar-se, começou ritualmente: 
“faz tempo que não vou ao dentista”. Insistiu-se para que esclarecesse seus incômodos bucais. "Tenho um resto de raiz, bolha com pus, nevralgia com gelado, amarelamento dos dentes e mau hálito. Também tive um inchaço no rosto faz um tempo". Falava com espontaneidade dos problemas de saúde e da recente busca do casal por "check up".

No LHC, relatou bronquite, rinite, sinusite, taquicardia, pontadas no peito e história familiar de hipertensão. "Tomei muitos corticóides e tive aumento de peso. E estou injuriada com isso". Sofria com insônia "principalmente em época de prova”. Reclamou de frequentes dores de cabeça em região frontal e base do crânio, piorando ao final do dia, mas não associava as dores a nenhuma situação, pessoa ou sentimento. Estudava em curso noturno para formação de técnicos em enfermagem. Não trabalhava, passando o dia sozinha em casa.

No EF, havia presença de raízes residuais, fístula na região de pré-molar superior. À palpação dos músculos mastigatórios e ATM, saltou da cadeira odontológica acusando dor. Perguntouse sobre sua rotina e suas preocupações. Falou sobre seus temores e do desejo de conquistar um emprego, via concurso público, num município vizinho. Ao final da consulta, solicitou-se que tentasse associar os episódios de dor de cabeça a alguma situação, pessoa ou sentimento e que retornasse.

Retornou após 02 meses. Animada, relatou que as dores de cabeça haviam cessado. "Consegui um emprego! Cuido de um idoso em fase terminal de doença grave”. Iniciou-se seu tratamento pela remoção das raízes residuais. No $6^{\circ}$ encontro, contou que abandonou o emprego por que a família do idoso não realizava os pagamentos no prazo combinado.

\section{Cicatriz, 29 anos}

No $1^{\circ}$ encontro, trazia à mão um encaminhamento da equipe do PSF local: "Cáries em pré-molares inferiores e outros. Refere dor”. Veio junto com a filha caçula (1 ano e meio). A menina, irrequieta, dificultou a consulta. Não houve referência a problemas de saúde. Apesar do encaminhamento, perguntou-se sobre suas queixas/incômodos. "Sinto dor nos dentes quando como e quando puxo o ar pela boca. Também, já perdi emprego por não ter os dentes em perfeito estado".

Ao EF, verificou-se gengivite intensa com muito sangramento à sondagem, edema, cálculo abundante, raízes residuais, placa visível e grande destruição coronária dos incisivos superiores e inferiores.

Com a ajuda do espelho, discutiu-se e negociou-se o tratamento explicando-lhe que, com sua atual condição bucal, não era aconselhável iniciar uma intervenção restauradora. Solicitouse que retornasse deixando o bebê aos cuidados de alguém de confiança a fim de iniciar o tratamento necessário com maior tranqüilidade.

Após 01 mês, retornou bastante abatida. Passara por uma entrevista de emprego. A vaga, auxiliar de produção, lhe foi recusada. Segundo ela, por causa de sua condição bucal. "Eu não imaginava que isso acontecia de verdade. Preciso do emprego". É casada há 10 anos. O marido estava desempregado. Tem 06 filhas. O esposo a culpa a cada gestação e se recusa a realizar vasectomia, enquanto ela estava decidida a fazer laqueadura para evitá-las. As intervenções clínicas iniciaramse pelo tratamento periodontal. Havia menor inflamação gengival. Mas não era possível restaurar os dentes anteriores como ela desejava.

No $3^{\circ}$ encontro, ansiava pelo tratamento restaurador. Ao EF, verificou-se que a inflamação gengival persistia em menor intensidade.

Três meses após o $1^{\circ}$ encontro, retornou. Era consulta de sua filha de 03 anos. Mas ela solicitou atendimento porque, na semana seguinte, passaria por nova entrevista de emprego. Não queira ser rejeitada novamente. Iniciou-se a restauração em resina composta dos incisivos. Nesse mesmo dia, muito confiante, informou que fizera os exames necessários para liberação da cirurgia de laqueadura.

\section{Forrest Gump, 47 anos}

No $1^{\circ}$ encontro, realizado em agosto em consulta de urgência, chegou bastante agitado. Sua voz era fanhosa. Perguntado sobre sua queixa/ incômodo, falou longamente e com muita empolgação sobre seus problemas e sua vida. Sua queixa relacionava-se ao incômodo resultante de exodontia realizada meses antes. Desenvolveu sinusite devido a uma comunicação buco-sinusal. "Depois que tirei o dente, começou a sair água pelo nariz, arroz. Não consigo mais falar direito. Não posso olhar para o chão porque me dói muito a cabeça”. No Procon, prestou reclamação da clínica privada onde realizou a cirurgia mas não houve resolução do problema. Além da comunicação buco-sinusal, se queixava das gengivas inchadas, da mobilidade dentária, do sangramento gengival e da sensibilidade dentinária 
ao quente e ao frio. Contou que, quando jovem, limpava os dentes com bombril e lixa d'água. Atualmente, adotou o clip como instrumento de limpeza. Relatou com detalhes exames médicos, viagens de São Paulo a Pernambuco e à cidade natal. Foi preciso interrompê-lo várias vezes solicitando que com brevidade contasse sua história clínica. No PU, as anotações referiam-se ao ano de 2007. Além da saúde bucal, consultava-se regularmente com a psiquiatra da UBS e com uma otorrinolaringologista da rede privada.

Definiu-se como "uma pessoa muito indecisa e ansiosa. Vivo do passado e tenho saudades da minha terra". É migrante nordestino e trabalhava como segurança da creche do bairro. Referia desânimo intenso e muita instabilidade, chorando a todo momento e por qualquer motivo. Estava sob medicação antidepressiva mas desenvolveu reação alérgica ao medicamento que fora suspenso um mês após o início do tratamento. Perguntado sobre o motivo do desânimo falou: "É a mulher que está me irritando. Me trata como um filho. É 13 anos mais velha do que eu”. Casados há 07 anos, dizia que estavam juntos porque ela insistia. Reclamou que a esposa ficava rastreando suas saídas. "Ela já me ajudou muito quando cheguei à São Paulo. Mas hoje vivemos como mãe e filho. Ela não aceita isso".

Ao EF, verificou-se: comunicação buco-sinusal em região de pré-molar, cálculo supra gengival, mobilidade dentária e problemas periodontais. Solicitou-se que retornasse trazendo radiografia panorâmica sendo também encaminhado para o Serviço de Cirurgia Oral Menor do CEO.

No $2^{\circ}$ encontro, trouxe a radiografia e uma carta da otorrinolaringologista solicitando o fechamento da comunicação buco-sinusal prévio ao tratamento da sinusite. Relatou que o cirurgião-dentista do CEO aconselhou a realização do tratamento da sinusite antes da cirurgia. Estava inseguro e queria resolver seu problema. Optou-se pela tentativa de fechamento da comunicação buco-sinusal. No $3^{\circ}$ encontro, ao E.F, verificou-se que a tentativa de fechamento da comunicação fora mal sucedida. Chegou-se à conclusão de que não seria possível realizar novas tentativas na UBS. Aconselhou-se Forrest Gump a procurar novamente o CEO.

\section{Insegurança. A porta das decisões, A., 30 anos e filhas, C. e B., 06 anos}

No $1^{\circ}$ encontro, realizado em setembro em consulta agendada, C. e B. vieram junto com a mãe, A. As meninas tinham consultas marcadas no mesmo dia, mas para horários diferentes. São gêmeas univitelinas e tinham um irmão com menos de 06 meses de idade. Indagou-se sobre vida escolar, familiar, alimentação e sobre o desenvolvimento das meninas. Insegurança relatou que C. rangia os dentes e tinha enurese noturna "Por isso, todas as noites usa fralda para dormir. Têm bom apetite e não têm problemas de saúde". Receberam aleitamento materno por pouco tempo. "Tive pouco leite", disse. Indagou-se sobre o uso de mamadeira. "Ainda tomam 02 vezes por dia, com leite e achocolatado". Mas, segundo A., só tomam mamadeira em casa, "quando estão na casa da avó não pedem".

Conversou-se com C. sobre seu desenvolvimento bucal e a suspensão do uso da mamadeira. A. contou que gostaria de suspender o uso das mamadeiras, "mas tenho medo de tirar delas". Ela tinha receio de magoar as meninas negando algo de que elas tanto gostavam. "Posso até tirar mas e se elas me pedirem a mamadeira de novo?" Explicou-se que não havia motivo para manter o hábito apresentando-lhe alguns argumentos para enfrentar a suspensão, aconselhando-se que não seria preciso barganhar com elas.

No decorrer da consulta, A. sentiu-se apta a negar a mamadeira às filhas. "Quando chegar em casa, vou jogar as mamadeiras fora!" "Não, mãe... Deixa eu brincar com ela", disse C. "Não, C. Brincar não. Se essas mamadeiras ficarem em casa, posso voltar atrás deixando que vocês voltem a mamar”. Sugeriu-se que as meninas entregassem as mamadeiras na próxima consulta, o que prontamente foi aceito por C. Combinouse que C. conversaria com B. e que, na consulta de B., elas entregariam as mamadeiras. A. estava satisfeita com o desfecho e quanto à decisão tomada. No mesmo dia, ao final da consulta, B. retirou da bolsa da mãe uma sacola plástica e a deixou sobre a mesa. Eram as 02 mamadeiras.

\section{Vidas Secas. Dentre os pobres os miseráveis, S., 27 anos; filhos: C. e V., 08 e 05 anos; filha: J. 07 anos}

No $1^{\circ}$ encontro, realizado em agosto em consulta agendada, C., J. e V. vieram junto com a mãe. Como tinham idades muito próximas, optou-se por chamar todos ao mesmo tempo. Morenos e franzinos. Tímidos, pouco falavam. J., pele e osso, sorriu muito. C., cabisbaixo, reclamou de dor de cabeça.

Traziam à mão um encaminhamento da equipe do PSF local: "dentes cariados". Apresentavam baixo peso evidente. Indagou-se sobre a 
opinião do médico em relação à saúde das crianças. "Diz que estão bem. Mas acho que eles não estão. Quero voltar a consultar com o pediatra daqui". Apesar do encaminhamento, perguntouse sobre suas queixas/incômodos. V. era o único que se queixava em relação à boca e dentes, segundo S. Em relação a J., queixava-se de sua teimosia e desatenção, motivos pelos quais desejava consultá-la com a psicóloga. Já em relação a C., a preocupação referia-se a tremores nas mãos, palidez e feridas na pele. Segundo registros no PU, aos 02 anos de idade, J. sofreu de desnutrição. "Só tomava água e chá". Sobre alimentação, S. relatou: "Eles são difíceis para comer. J. come arroz, feijão, sopão 'maggi'. V. só come doce. Leite está difícil para comprar". No LHC, S. relatou que J. reclamava de cansaço e de dor ao urinar. V. foi o único amamentado por mais de 02 anos.

C. apresentava sobrenome diferente de J. e V. Eram irmãos apenas por parte de mãe. C. é filho do $1^{\circ}$ casamento de $S$. J., V. e um bebê são filhos de seu relacionamento atual. Viviam juntos num único cômodo no mesmo terreno onde estava construída a casa do pai de S. "O pai de C. morreu. Foi assassinado". Não entrou em detalhes apenas comentou que ele estava ligado ao tráfico de drogas ilícitas na região. Indagou-se sobre seu relacionamento com o $2^{\circ}$ marido e da relação dele com as crianças. S. contou que ele era usuário de drogas e bebia muito. Ele tem emprego. "Mas mais falta do que vai". Ela trabalhava como diarista pela Frente de Trabalho (FT). "Antes, eu puxava carrinho". S. reclamou que com o novo emprego, o serviço de assistência social da região cancelara a entrega de cesta básica. Eram apenas 09 meses de contrato pela FT recebendo 01 salário mínimo. Dizia que, no início do casamento seu $2^{\circ}$ marido tratava C. como um filho. "Mas, agora, ele reclamava que C. tinha jeito de bicha". Indagou-se a relação do marido com C. para investigar se havia caso de agressão ao menor. "Não. Ele não bate em nenhum deles". Seus olhos baixaram. Foi preciso perguntar-lhe se o marido a agredia fisicamente. "Sim. Às vezes. Quando ele bebe". Relatou que, por vezes, ele a agrediu na presença dos filhos. Contou que saiu de casa há cerca de 01 ano. Abandonou-o. Mudou-se para uma favela em São Paulo. "Mas ele foi atrás de nós. Quebrou meu barraco e me trouxe de volta pra cá". Eram acompanhados pelo conselho tutelar. "Querem levar as crianças para um abrigo. Mas enquanto puder trabalhar, eles ficam comigo".

No EF, verificou-se cárie crônica e aguda, cavitações, placa visível e manchas brancas. Conversou-se sobre as intervenções clínicas necessárias em cada uma das crianças e solicitou-se retorno sugerindo que procurassem o pediatra da UBS.

S. apresentava um sofrimento bucal intenso. Não foi examinada, mas observou-se que ela era portadora de prótese removível provisória. Ela mesma fizera referência à sua condição bucal após o EF dos filhos. Não mantinha boa limpeza, tinha mau cheiro na boca. Falou de sua falta de vontade em se cuidar. "Não quero me arrumar. Não escovo os dentes". Nada a animava a não ser sobreviver pelos filhos. Perguntou se seu mau hálito poderia decorrer da hepatite que ela contraíra em relação sexual com o marido. Mas era muito mais provável que o mau cheiro resultasse da inflamação e áreas de necrose gengivais. Foi preciso interromper a consulta. $\mathrm{O}$ caso foi encaminhado para a equipe de enfermagem, que resultou na entrega de leite para a família. Porém S. insistia em terminar seu desabafo: "Meu marido não quer mais me beijar. Ele diz que eu cheiro mal".

Quatro meses depois, retornaram. À mesa de consulta, $S$. disse que, em breve, se mudaria para uma favela na zona norte de São Paulo. "Minha tia tem um barraco lá. Só estou esperando o madeirite e as telhas". Indagada se a mudança seria tranqüila, S. afirmou que havia conversado com o marido e que estavam de comum acordo; ela se mudaria com as crianças e ele não iria mais atrás.

\section{Discussão}

O Estado brasileiro, através do SUS, se responsabilizou pela atenção à saúde de sua população assumindo a complexidade do processo saúdedoença. No nível primário do SUS, as ações de caráter individual ou coletivo envolvem: promoção de saúde, prevenção de doenças, diagnóstico, tratamento e reabilitação numa cadeia progressiva que garante o acesso aos cuidados e às tecnologias necessárias e adequadas à prevenção e ao enfrentamento das doenças para o prolongamento da vida ${ }^{10}$.

A UBS, o primeiro nível de contato de indivíduos, da família e da comunidade com o SUS, é um lugar com potencial gerador de encontros e produção de subjetividades ou de agenciamentos tecnossemiológicos ${ }^{11}$. Sem dúvida, a atividade assistencial mais realizada na UBS é a clínica, por isso a tomamos como objeto de investigação para compreendê-la como espaço de intersubjetivação dos sujeitos cirurgião-dentista e usuário na tentativa de experimentar tecnologias de cuidado (compreendendo a anamnese e a te- 
rapêutica) para inovação da atenção em saúde bucal na $\mathrm{AB}$, reorientado pela lógica da promoção da saúde.

Sabemos que a comunicação na consulta clínica, além das características individuais dos profissionais, é influenciada por: condições de trabalho oferecidas, disposição de equipamentos, infraestrutura da UBS e organização do trabalho em saúde.

Toda consulta é singular pois é o momento de encontro entre dois sujeitos singulares ${ }^{12}$ e em que um deles, o usuário, procura o cuidado e a resolução de seus problemas de saúde. Esse momento é dependente de fatores como lugar e situação, quer dizer, a consulta realizada num serviço de pronto atendimento é diferente da realizada na UBS; contudo, apresenta um eixo comum: a identificação de um problema e a busca de meios para resolvê-lo ${ }^{13}$.

Classicamente, definem-se 04 momentos da consulta: anamnese; EF; formulação do diagnóstico e elaboração da terapêutica. A anamnese objetiva iniciar o diagnóstico de um agravo por meio da formação da história do usuário e de sua doença/queixa. Possui formas e técnicas corretas que, ao serem aplicadas, proporcionam melhor aproveitamento do tempo disponível para o atendimento, produzindo o diagnóstico seguro e o tratamento adequado. Quando bem conduzida pode ser responsável por $85 \%$ do diagnóstico na clínica, liberando $10 \%$ para o EF e apenas 5\% para os exames complementares ${ }^{14}$.

A boa anamnese prescinde de 05 passos fundamentais: acolhimento do usuário e sua queixa; construção da história da doença/queixa atual; LHC; interrogatório sobre os diferentes aparelhos; história alimentar, familiar e socioeconômica. Para isso, é necessário realizar a escuta do usuário e manter diálogo com o mesmo assim como anotar sistematicamente e com clareza, no PU, as informações obtidas. A não anotação de dados, como no caso de Menina-Moça, sinaliza uma dupla negação da história da queixa. Negação do profissional e negação do usuário. Um PU mal preenchido e uma história clínica mal investigada podem comprometer a relação de cuidado.

É preciso, também, desmitificar a crença de que escuta e diálogo são dons. A capacidade de diálogo é essencial ao processo de cuidado, exige disposição (e técnica) para escuta e, aceitação do outro e de seus saberes ${ }^{15}$. Há posturas profissionais e técnicas de comunicação que facilitam a conversa entre profissional e usuário e que ilustramos por meio das hestórias patográficas. Dentre as posturas profissionais, citamos: a conside- ração incondicionalmente positiva (aceitação do outro), a empatia ${ }^{14}$ e o reconhecimento do usuário como um sujeito portador de direitos.

As habilidades de comunicação e raciocínio clínico são de dimensão relacional e técnica, logo, tecnologias leves ${ }^{9}$ que têm por objetivo maior acolher o usuário e interferir na evolução do sofrimento do mesmo restabelecendo a homeostasia corporal e produzindo vínculo entre os sujeitos e os serviços de saúde.

Há componentes básicos para comunicação eficiente na clínica denominadas habilidades "não"-seletivas e seletivas de escuta. As primeiras são: comportamento no atendimento; comportamento verbal e não-verbal; acompanhamento verbal e silêncios/pausas. E as segundas são: fazer perguntas abertas (iniciando as interrogações com: como?; o que você acha que pode ser ou fazer?; evitando reprimir o usuário com 'porquês'); parafrasear o conteúdo (reproduzindo/traduzindo o relato em tom hesitante ou afirmativo); exprimir sentimentos (manifestando empatia); concretizar (ajudando o usuário a ser mais preciso) e resumir/sumariar a história contada ${ }^{15}$.

Nas consultas que realizamos, optamos por não utilizar questionários com questões fechadas nem odontograma. O uso de roteiros/protocolos na anamnese é bastante útil na clínica, porém, pode representar uma armadilha para o profissional de saúde. Primeiro, porque as perguntas fechadas restringem e direcionam as respostas dos usuários e, segundo, porque o clínico pode incorporar esses algoritmos escutando e perguntando somente o que está contido nos roteiros ${ }^{14}$ de maneira que tudo que não está representado como pergunta protocolar produza certa insegurança e o profissional de saúde comece a evitar os desvios necessários na investigação de uma história clínica ${ }^{7}$.

A possibilidade de desviar, a abertura de olhos e ouvidos para a vida do outro podem fazer com que questões como dependência química, violência doméstica e sexual, rendimento escolar e conflitos familiares emerjam como demandas de consulta envolvendo conhecimentos em psicologia, sociologia e antropologia e para os quais ainda não recebemos a devida formação ${ }^{14}$. Tais depositações que podem ser sociais, familiares e psíquicas, apresentadas no relato de uma história de vida durante a anamnese, são denúncias da realidade social de uma determinada comunidade num determinado tempo. São a emergência de um problema que, se melhor investigado e compreendido, pode fornecer respostas para possibilitar uma abordagem mais integral. 
É preciso apontar que há diferenças na consulta de crianças e adultos. Os conceitos básicos para execução da anamnese são os mesmos para todos os ciclos vitais. As crianças, geralmente, vêm acompanhadas pelo responsável que traduz seus sintomas e relata suas queixas. Os pais, em geral, procuram cuidado médico em busca de respostas para sua preocupação em relação ao desenvolvimento e educação infantil. O profissional atencioso deve escutar as queixas e investigar os modos e as condições de vida (como no caso de Vidas Secas) e as relações afetivas e emocionais da família (como no caso de Insegurança) para compreender o adoecimento infantil. Dentre as atribuições do clínico destacamos o apoio e o encorajamento dos pais, oferecendolhes estímulo para resgatar sua autoestima ${ }^{16}$ assim como o reconhecimento e a diferenciação entre problemas de natureza clínica e psicossociais, proporcionando os devidos encaminhamentos junto com profissionais de outras áreas.

$\mathrm{Na}$ relação do profissional com o usuário adulto, inicialmente, destacamos que o mesmo, pelo maior tempo de vida, pode deixar lacunas no LHC. Durante a anamnese, o usuário, através de fragmentos de memória, vai apresentando um relato não linear de sua vivência (como no caso de Forrest Gump). Contudo, há outros aspectos relevantes neste tipo de consulta que devem ser observados, tais como: escuta da queixa e da expectativa do usuário em relação à consulta/serviço de saúde, motivação do mesmo em relação aos cuidados corporais com estimulação de sua autonomia, privacidade no consultório que garanta a confidencialidade do relato, disposição de mesas, cadeiras e equipamentos. Neste trabalho, utilizamos um espelho $13 \times 17 \mathrm{~cm}$ para auxiliar o usuário na observação, discussão e negociação do projeto terapêutico. $\mathrm{O}$ uso do espelho foi facultativo e acreditamos que o fato do usuário se ver (ou se examinar com apoio técnico-especializado) durante o $\mathrm{EF}$ contribuiu para ampliar sua capacidade de autonomia além de objetivar o diálogo entre profissional e usuário.

Além disso, optamos por realizar parte da consulta fora da cadeira odontológica, isto é, o usuário ao ser recebido no consultório era convidado a sentar-se frente a uma mesa para consulta. A diferença na recepção e na disposição dos móveis e equipamentos foram apontadas como positivas e percebemos que o simples fato de não os recebermos na cadeira odontológica já eliminava grande parte do sofrimento gerado pela ansiedade em relação à consulta.

Ouvir o usuário e os motivos que o trouxeram à consulta são o primeiro passo para efeti- var o diálogo e o vínculo. Compreender suas expectativas em relação ao profissional e ao serviço de saúde e examiná-lo procurando responderlhes às angústias possibilitam que conjuntamente, cirurgião-dentista e usuário, construam uma agenda terapêutica que contemple as necessidades de tratamento identificadas pelo profissional e as demandas específicas do usuário.

Contudo, nem sempre as demandas apresentadas pelos usuários são do tipo queixa-conduta. O que fazer quando há reclamação sobre a rejeição na entrevista de emprego? Quando há confidência do desgosto com o casamento? Quando há queixa de dor de cabeça que não apresenta fator desencadeante bucal ou dentário? Para compreender essas demandas, há 03 papéis possíveis a ser desempenhados pelo profissional de saúde: o especialista, o consultor e o instrutor ${ }^{17}$.

O profissional no papel de especialista responde a demandas claras, à queixa/problema de ordem biológica de um usuário dependente. Menina-Moça, Caçadora de Si, Forrest Gump, Primavera nos Dentes, Mama África, Vidas Secas, Cicatriz e Insegurança apresentavam queixas aparentemente claras dependentes de ação profissional (encaminhamento, curetagens, restaurações, extrações). Mas ao aprofundarem-se as investigações, deparávamos com problemas de natureza diferenciada não estruturados biologicamente. Exemplo: Caçadora de Si e o resgate dos cuidados corporais ou o caso de Insegurança e a suspensão do uso de mamadeira pelas filhas. Nesse caso, o profissional desempenha um papel de consultor colaborando com o usuário na busca de solução sendo imprescindível que ambos sejam ativos no processo de cuidado, e a construção da agenda terapêutica passa a ser compartilhada e realizada deliberativamente. Já no caso de Cicatriz, Mama África, Forrest Gump, Primavera nos Dentes, os problemas, quando melhor investigados, denunciam um pano de fundo psicológico ou pessoal. As queixas sobre trabalho, situação de desemprego e relacionamentos conjugais não contam com o imediatismo das prescrições médicas. Configuram-se como relatos, histórias de vida que devem ser ouvidas e compreendidas. Nesses casos, o profissional assume o papel de instrutor: ouve o relato, discute os problemas apresentados e identificados mas apenas pode apoiar o usuário na tomada de responsabilidade e decisão sobre seu processo de busca de soluções.

Esclarecemos que adotou-se o nome clínica de odonto-estomatologia ao invés da tradicional denominação clínica odontológica porque compreendemos a Odontologia como sub-especiali- 
dade da Estomatologia (relação entre o todo e a parte), e não o contrário, como tem sido difundido sócio-historicamente pela corporação odontológica e centros formadores.

Acreditamos que para mudar o processo de cuidado é preciso romper com a circunscrição colocada pelos conceitos nosológicos da Odontologia $^{18}$ e que hegemonicamente a orientam a saber: o centramento dentário e a operatória dentária como a priori do diagnóstico e da terapêutica; a ênfase no comportamento individual do usuário e nas teorias microbiológicas para intervenção em ações de promoção da saúde; a cárie dentária como patologia-mãe (como se todos as outras patologias bucais fossem decorrentes desta primeira patologia). Para isso, faz-se necessário optar por outros referenciais teórico-metodológicos: a SBC e a bucalidade ${ }^{8,18}$. É a partir do entendimento sobre a saúde como um estado de equilíbrio instável ${ }^{12}$ determinado social e subjetivamente por um homo sapiens-demens ${ }^{19}$, da ressignificação das funções sociais da boca, da compreensão do adoecimento buco-dentário e da constituição do caso clínico na anamnese que se estabelecerá uma outra posição para a clínica.

\section{Considerações finais}

A UBS, primeiro nível de contato de indivíduos, da família e da comunidade com o SUS, é um lugar com potencial gerador de encontros e produção de subjetividades.

A anamnese, momento fundamental da clínica, tem por objetivo iniciar o diagnóstico seguro e o tratamento adequado de um agravo através da formação da história do usuário e de sua doença/queixa e, quando conduzida, pode ser responsável por $85 \%$ do diagnóstico na clínica. Lembramos, como colocado na oficina sobre clínica e subjetividade, realizada no Congresso da Abrasco, em 2006, que é na anamnese que se constitui o caso clínico, é na anamnese que aparece o doente com sua doença ${ }^{8}$.
A comunicação durante a consulta, além das características individuais dos profissionais, é influenciada pelas: condições de trabalho oferecidas, disposição de equipamentos, infraestrutura da UBS e organização do trabalho em saúde bucal.

As habilidades de comunicação e raciocínio clínico na consulta são tecnologias leves que objetivam acolher o usuário e interferir na evolução do seu sofrimento restabelecendo a homeostasia corporal e produzindo vínculo entre os sujeitos e os serviços de saúde. Para compreensão do outro é preciso ampliar o olhar e a escuta profissional o que implica na assunção de novos referenciais teóricos e na modificação significativa de linguagem e abordagem clínicas.

Percebemos que o vínculo entre o profissional e o usuário na $\mathrm{AB}$ é construído a cada encontro, a cada negociação terapêutica (como uso de medicamento ou necessidade de encaminhamento) resultando do diálogo franco, da assunção de responsabilidades tanto do profissional quanto do usuário e da resolução das suas queixas e necessidades.

\section{Colaboradores}

RS Barros e C Botazzo participaram igualmente de todas as etapas da elaboração do artigo. 


\section{Referências}

1. Brasil. Ministério da saúde (MS). Política Nacional de Saúde Bucal. Brasília, DF: Coordenação de Saúde Bucal; 2004. mimeo.

2. $\quad 1^{\text {a }}$ Conferência Nacional de Saúde Bucal. Relatório Final. Brasília, DF; 1986. mimeo.

3. Narvai PC. Odontologia e saúde bucal coletiva. $2^{\text {a }}$ ed. São Paulo: Santos; 2002.

4. Botazzo C, Manfredini MA, Narvai PC, Frazão P. Saúde Bucal Coletiva. São Paulo, SP; 1988. mimeo.

5. Zegarelli EV, Kutscher AH, Hyman GA. Diagnóstico das doenças da boca e dos maxilares. $2^{\text {a }}$ ed. Rio de Janeiro: Guanabara Koogan; 1982.

6. Botazzo C. Unidade Básica de Saúde - A porta do sistema revisitada. Bauru: EDUSC; 1999.

7. Souza ECF. Bocas, câncer e subjetividades. Patografias em análise [tese]. Campinas: Faculdade de Ciências Médicas da Universidade Estadual de Campinas; 2003.

8. Botazzo et al. Oficina "Subjetividade e Prática Odontológica". Relatório Final. Pré Congresso do $11^{\circ}$ Congresso Mundial de Saúde Pública e $8^{\circ}$ Congresso Brasileiro de Saúde Coletiva. Rio de Janeiro, RJ 2006. [acessado 2004 Mar 07] Disponível em: http:/ /saudecoletiva2006.com.br/Oficina_Sujetividade\% $20 \% 20$ Pratica $\% 20$ Odontologica.pdf.

9. Merhy EE. Saúde: a cartografia do Trabalho Vivo. $2^{a}$ ed. São Paulo: Hucitec; 2005.

10. O SUS de A a Z: garantindo saúde nos municípios. Ministério da Saúde. Conselho Nacional de Secretários Municipais de Saúde. Brasília, DF; 2005. mimeo

11. Teixeira RR. Agenciamentos tecnosemiológicos e produção de subjetividade: contribuições para o debate sobre a trans-formação do sujeito na saúde. Cien Saude Colet 2001; 6(1):49-61.

12. Cunha GT. A construção da clínica ampliada na Atenção Básica. 2a ed. São Paulo: Hucitec; 2007.

13. Sucupira ACSL. Estrutura da consulta. In: Leite AJM, Caprara A, Coelho Filho JM, organizadores. Habilidades de comunicação com pacientes e famílias. São Paulo: Sarvier; 2007. p. 11-46.
14. Anamnese. [acessado $2007 \mathrm{dez} 31$ ]. Disponível em: http://pt.wikipedia.org/wiki/Anamnese_(medicina). 15. Van Der Molen HT, Lang G. Habilidades da

15. escuta na consulta médica. In: Leite AJM, Caprara A, Coelho Filho JM, organizadores. Habilidades de comunicação com pacientes e famílias. São Paulo: Sarvier; 2007. p. 47-66.

16. Leite AJM, Carmo e Sá HL, Bessa OAC. Habilidades de comunicação na consulta com crianças. In: Leite AJM, Caprara A, Coelho Filho JM, organizadores. Habilidades de comunicação com pacientes e famílias. São Paulo: Sarvier; 2007. p. 91-137.

17. Van Der Molen HT. Habilidades de aconselhamento. In: Leite AJM, Caprara A, Coelho Filho JM, organizadores. Habilidades de comunicação com pacientes e famílias. São Paulo: Sarvier; 2007. p. 67-77.

18. Botazzo C. Saúde Bucal e Cidadania. Transitando entre a teoria e a prática. In: Pereira AC, organizador. Odontologia em Saúde Coletiva. Planejando Ações e Promovendo Saúde. Porto Alegre: ArtMed; 2003. p. 17-27.

19. Morin E. Amor Poesia Sabedoria. 2a ed. Rio de Janeiro: Bertrand Brasil; 1999.

Artigo apresentado em 17/03/2009

Aprovado em 23/06/2009

Versão final apresentada em 26/06/2009 